Pacific Journal of Mathematics

A VERY WEAK TOPOLOGY FOR THE MIKUSINSKI FIELD OF 


\title{
A VERY WEAK TOPOLOGY FOR THE MIKUSINSKI FIELD OF OPERATORS
}

\author{
HARRIS S. SHULTZ
}

\begin{abstract}
Using a generalized Laplace transformation the Mikusinski field is given a topology $T$ such that sequences which converge in the sense of Mikusinski converge with respect to $T$, such that the mapping $q \rightarrow q^{-1}$ is continuous and such that the series $\sum(-\lambda)^{n} s^{n} / n$ ! converges to the translation operator $e^{-\lambda s}$.
\end{abstract}

In [3] it is shown that the notion of convergence defined in [8] for the Mikusinski field of operators is not topological. Topologies for the Mikusinski field are given in [1], [3], and [9]. In the present paper we endow this field with a topology $T$ such that sequences which converge in the sense of Mikusinski converge with respect to $T$, such that the identity

$$
e^{-\lambda . s}=\sum_{k=0}^{\infty} \frac{(-\lambda)^{k}}{k !} s^{k} \quad(\lambda>0)
$$

holds and such that the mapping $q \rightarrow q^{-1}$ is continuous. The author wishes to acknowledge that this paper constitutes proofs of assertions proposed by Gregers Krabbe [7].

Let $L$ denote the family of complex-valued functions which are locally integrable on $[0, \infty)$. Under addition and convolution $L$ is an integral domain. If $Q$ denotes the quotient field of $L$ then $Q$ is the Mikusinski field of operators. Elements of $Q$ will be denoted $\{f(t)\}$ : $\{g(t)\}$ and the injection of $L$ into $Q$ will be denoted $f \rightarrow\{f(t)\}$. We define $S$ to be the set of all $f$ in $L$ for which the integral

$$
\int_{0}^{\infty} e^{-z t} f(t) d t
$$

converges for some $z$. For $f$ in $S$ let

$$
\bar{f}(z)=\int_{0}^{\infty} e^{-z t} f(t) d t
$$

and $\bar{S}=\{\bar{f}: f \in S\}$. Each element of $\bar{S}$ is holomorphic in some right half-plane. Let $B$ denote the set of all sequences $\left(\bar{f}_{n}\right)$ of nonzero elements of $\bar{S}$ for which there exists $f$ in $L$ such that

$$
f_{n}=f \text { on }(0, n) \quad \text { for all } n \text {. }
$$

For a given $f$ the set of all elements of $B$ satisfying (1) will be 
denoted $\hat{f}$. Let $B^{*}$ denote the set of all elements $\left(\bar{g}_{n}\right)$ of $B$ such that $\left(\bar{g}_{n}\right) \in \hat{g}$ where $g$ is a nonzero element of $L$. Finally, let $X$ denote the set of all sequences $\left(\bar{f}_{n} / \bar{g}_{n}\right)$ where $\left(\bar{f}_{n}\right) \in B$ and $\left(\bar{g}_{n}\right) \in B^{*}$. Then $X$ consists of sequences of functions which are meromorphic in some right half-plane.

Lemma. Let $\left(\bar{f}_{n}\right) \in \hat{f},\left(\bar{g}_{n}\right) \in \hat{g},\left(\bar{F}_{n}\right) \in \hat{F}$ and $\left(\bar{G}_{n}\right) \in \hat{G}$ and suppose that $g$ and $G$ are nonzero elements of $L$. Then $f_{n}^{*} G_{n}=F_{n}^{*} g_{n}$ on $(0, n)$ for all $n$ if and only if $\{f\{t\}\}:\{g(t)\}=\{F(t)\}:\{G(t)\}$.

Proof. Since $f_{n}^{*} G_{n}=f^{*} G$ on $(0, n)$ and $F_{n}^{*} g_{n}=F^{*} g$ on $(0, n)$, the statements $f_{n}^{*} G_{n}=F_{n}^{*} g_{n}$ on $(0, n)$ for all $n$ and $f^{*} G=F^{*} g$ are equivalent.

Theorem 1. There exists a mapping $\Phi$ of $X$ onto $Q$ such that if $q$ belongs to $Q$, say $q=\{f(t)\}:\{g(t)\}$, and if $\left(\bar{f}_{n}\right)$ and $\left(\bar{g}_{n}\right)$ belong, respectively, to $\hat{f}$ and $\hat{g}$, then $\Phi\left(\left(\bar{f}_{n} / \bar{g}_{n}\right)\right)=q$.

Proof. Let $\left(\bar{f}_{n} / \bar{g}_{n}\right) \in X$. If $\left(\bar{f}_{n}\right) \in \hat{f}$ and $\left(\bar{g}_{n}\right) \in \hat{g}$ define

$$
\Phi\left(\left(\bar{f}_{n} / \bar{g}_{n}\right)\right)=\{f(t)\}:\{g(t)\} \text {. }
$$

If $\left(\bar{f}_{n} / \bar{g}_{n}\right)=\left(\bar{F}_{n} / \bar{G}_{n}\right)$ then $\bar{f}_{n} \bar{G}_{n}=\bar{F}_{n} \bar{g}_{n}($ all $n)$, that is, $\overline{f_{n}^{*} G_{n}}=\overline{F_{n}^{*} g_{n}}$ (all $n$ ). Therefore, $f_{n}^{*} G_{n}=F_{n}^{*} g_{n}($ all $n$ ) and hence, by the lemma,

$$
\Phi\left(\left(\bar{F}_{n} / \bar{G}_{n}\right)\right)=\Phi\left(\left(\bar{f}_{n} / \bar{g}_{n}\right)\right) .
$$

Thus, $\Phi$ is well-defined. Now, for any $q \in Q$ there exist $f$ and $g$ in $L$ such that $q=\{f(t)\}:\{g(t)\}$. Let $\left(\bar{f}_{n}\right) \in \hat{f}$ and $\left(\bar{g}_{n}\right) \in \hat{g}$. Then $\left(\bar{f}_{n} / \bar{g}_{n}\right) \in X$ and $\Phi\left(\left(\bar{f}_{n} / \bar{g}_{n}\right)\right)=q$. Therefore, $\Phi$ is "onto."

For each nonempty open subset $\Omega$ of the complex plane let $M(\Omega)$ denote the set of all functions which are meromorphic in $\Omega$. We equip $M(\Omega)$ with the topology of uniform convergence on compact subsets of $\Omega$ with respect to the chordal metric. Thus $\varphi_{\mu} \rightarrow \varphi$ in $M(\Omega)$ if and only if

$$
\lim _{\mu}\left[\sup _{z \in K} \frac{\left|\varphi_{\mu}(z)-\varphi(z)\right|}{\sqrt{1+\left|\varphi_{\mu}(z)\right|^{2}} \sqrt{1+|\varphi(z)|^{2}}}\right]=0
$$

for all compact subsets $K$ of $\Omega$. Let $M=\bigcup \begin{aligned} & \mathrm{U} \\ & \text { L }\end{aligned}(\Omega)$ where $\Omega$ varies over the nonempty open subsets of the complex plane and equip $M$ with the finest topology for which all of the injections $M(\Omega) \rightarrow M$ are continuous. Let $Y$ denote the set of all sequences in $M$ and equip $Y$ with the product topology. We may then endow its subset $X$ with the relative topology. Finally, $Q$ is given the quotient topology (relative to $\Phi$ and the topology of $X$ ). Let $T$ denote this 
topology. Thus, $T$ is the finest topology on $Q$ for which the function $\Phi: X \rightarrow Q$ is continuous.

THEOREM 2. If $q_{k}$ converges to $q$ in the sense of Mikusinski then $q_{k}$ converges to $q$ with respect to the topology $T$.

Proof. Suppose $q_{k}$ converges to $q$ in the sense of Mikusinski. Then there exists $g, f$ and $f_{k}(k=1,2, \cdots)$ in $L$ such that $\{g(t)\} q=$ $\left\{f_{k}(t)\right\}$ and $\{g(t)\} q=\{f(t)\}$ and such that $f_{k}$ converges to $f$ uniformly on compact subsets of $[0, \infty)$. Define

$$
\bar{f}_{k, n}(z)=\int_{0}^{n} e^{-z t} f_{k}(t) d t
$$

and

$$
\bar{f}_{n}(z)=\int_{0}^{n} e^{-z t} f(t) d t .
$$

Then $\left(\bar{f}_{k, n}\right) \in \widehat{f}_{k}$ and $\left(\bar{f}_{n}\right) \in \hat{f}$. Moreover, $\bar{f}_{k, n}$ and $\bar{f}_{n}$ are entire functions and

$$
\lim _{k \rightarrow \infty}\left[\sup _{z \in K}\left|\bar{f}_{k, n}(z)-\bar{f}_{n}(z)\right|\right]=0 \quad(n=1,2, \cdots)
$$

for any compact set $K$. Let $\left(\bar{g}_{n}\right) \in \hat{g}$ and, for each $n$, choose a nonempty open set $\Omega_{n}$ such that $\bar{g}_{n}$ is holomorphic and nonvanishing in $\Omega_{n}$. Then $\bar{f}_{k, n} / \bar{g}_{n}$ is holomorphic in $\Omega_{n}$ and

$$
\lim _{k \rightarrow \infty} \bar{f}_{k, n} / \bar{g}_{n}=\bar{f}_{n} / \bar{g}_{n}
$$

in $M\left(\Omega_{n}\right)$ and therefore in $M$. Thus,

$$
\lim _{k \rightarrow \infty}\left(\bar{f}_{k, n} / \bar{g}_{n}\right)=\left(\bar{f}_{n} / \bar{g}_{n}\right) \text { in } X \text {. }
$$

But $\Phi\left(\left(\bar{f}_{k, n} / \bar{g}_{n}\right)\right)=q_{k}$ and $\Phi\left(\left(\bar{f}_{n} / \bar{g}_{n}\right)\right)=q$ by Theorem 1. Therefore, since $\Phi$ is continuous, it follows that

$$
\lim _{k \rightarrow \infty} q_{k}=q \text {. }
$$

Let us define

$$
\begin{aligned}
h_{\beta}(t) & =\frac{t^{\beta-1}}{(\beta-1) !} & & (\beta=1,2, \cdots) \\
s^{0} & =\text { the identity element of } Q & & \\
s^{\beta} & =\left\{h_{\beta}(t)\right\}^{-1} & & (\beta=1,2, \cdots) .
\end{aligned}
$$

We also define $e^{-\lambda s}=s\{f(t)\}$, where 


$$
f(t)= \begin{cases}0 & 0 \leqq t<\lambda \\ 1 & 0<\lambda \leqq t\end{cases}
$$

Then $s$ is the differential operator and $e^{-\lambda s}$ is the translation operator.

THEOREM 3. $e^{-\lambda s}=\sum_{k=0}^{\infty}(-\lambda)^{k} / k ! s^{k}$.

Proof. If $f$ and $h_{\beta}$ are defined as above then $\bar{f}(z)=e^{-\lambda z} / z$ and $\bar{h}_{\beta}(z)=z^{-\beta}(\beta=1,2, \cdots)$. Let

$$
\varphi_{k}(z)=\frac{(-\lambda)^{k}}{k !} z^{k} \quad(k=0,1,2, \cdots) .
$$

Then

$$
\frac{\bar{f}(z)}{\bar{h}_{1}(z)}=e^{-\lambda z}=\sum_{k=0}^{\infty} \varphi_{k}(z)
$$

where the convergence is uniform on compact sets. Therefore,

$$
\bar{f} / \bar{h}_{1}=\sum_{k=0}^{\infty} \varphi_{k} \quad \text { (convergence in } M \text { ) . }
$$

That is,

$$
\left.\bar{f} / \bar{h}_{1}=\lim _{N \rightarrow \infty} \sum_{k=0}^{N} \varphi_{k} \quad \text { (convergence in } M\right) .
$$

Thus,

$$
\left(\bar{f} / \bar{h}_{1}, \bar{f} / \bar{h}_{1}, \cdots\right)=\lim _{N \rightarrow \infty}\left(\sum_{k=0}^{N} \varphi_{k}, \sum_{k=0}^{N} \varphi_{k}, \cdots\right)
$$

where the convergence is in $X$. But $\Phi\left(\left(\bar{f} / \overline{h_{1}}, \bar{f} / \bar{h}_{1}, \cdots\right)\right)=e^{-\lambda s}$ and

$$
\Phi\left(\left(\sum_{k=0}^{N} \varphi_{k}, \sum_{k=0}^{N} \varphi_{k}, \cdots\right)\right)=\sum_{k=0}^{N} \frac{(-\lambda)^{k}}{k !} s^{k} .
$$

Since $\Phi$ is continuous it follows that

$$
e^{-\lambda s}=\lim _{N \rightarrow \infty} \sum_{k=0}^{N} \frac{(-\lambda)^{k}}{k !} s^{k} .
$$

Let $Q^{*}$ denote the set of nonzero elements of $Q$ and define $\Gamma$ : $Q^{*} \rightarrow Q^{*}$ by the equation $\Gamma(q)=q^{-1}\left(\right.$ all $q$ in $\left.Q^{*}\right)$.

THEOREM 4. The function $\Gamma$ is continuous.

Proof. Let $X^{*}=\left\{x \in X: \Phi(x) \in Q^{*}\right\}$. Since $Q^{*}$ has the quotient topology (relative to $\Phi$ and the topology of $X^{*}$ ) it suffices to show 
that the composition $\Gamma^{\circ} \Phi$ is continuous [5, p. 95, Theorem 9]. Suppose $x_{\mu}$ is a net in $X^{*}$ which converges to $x$ in $X^{*}$. Let $x_{\mu}=\left(\bar{f}_{\mu, n} / \bar{g}_{\mu, n}\right)$ and $x=\left(\bar{f}_{n} / \bar{g}_{n}\right)$. If $\left(\bar{f}_{\mu, n}\right) \in \hat{f}$ then $f_{\mu} \neq 0$ (since $\left.x_{\mu} \in X^{*}\right)$ and therefore $\left(\bar{f}_{\mu, n}\right) \in B^{*}$. Similarly, $\left(\bar{f}_{n}\right) \in B^{*}$. Therefore, $\left(\bar{g}_{\mu, n} / \bar{f}_{\mu, n}\right)$ and $\left(\bar{g}_{n} / \bar{f}_{n}\right)$ belong to $X^{*}$. Since $x_{\mu} \rightarrow x$ it follows that $\bar{f}_{\mu, n} / \bar{g}_{\mu, n} \rightarrow \bar{f}_{n} / \bar{g}_{n}$ in $M$ for each $n$. Therefore, for each $n$ there exists $\Omega_{n}$ such that

$$
\bar{f}_{\mu, n} / \bar{g}_{\mu, n} \longrightarrow \bar{f}_{n} / \bar{g}_{n}
$$

in $M\left(\Omega_{n}\right)$. Since the reciprocals $\bar{g}_{\mu, n} / \bar{f}_{\mu, n}$ and $\bar{g}_{n} / \bar{f}_{n}$ are also meromorphic in $\Omega_{n}$, the identity

$$
\frac{\left|\frac{1}{z}-\frac{1}{w}\right|}{\sqrt{1+\left|\frac{1}{z}\right|^{2}} \sqrt{1+\left|\frac{1}{w}\right|^{2}}}=\frac{|z-w|}{\sqrt{1+|z|^{2}} \sqrt{1+|w|^{2}}}
$$

implies that $\bar{g}_{\mu, n} / \bar{f}_{\mu, n} \rightarrow \bar{g}_{n} / \bar{f}_{n}$ in $M\left(\Omega_{n}\right)$ and therefore in $M$. Since this is true for each $n$ it follows that $\left(\bar{g}_{\mu, n} / \bar{f}_{\mu, n}\right) \rightarrow\left(\bar{g}_{n} / \bar{f}_{n}\right)$ in $X^{*}$. Therefore, $\Phi\left(\left(\bar{g}_{\mu, n} / \bar{f}_{\mu, n}\right)\right) \rightarrow \Phi\left(\left(\bar{g}_{n} / \bar{f}_{n}\right)\right)$ in $Q^{*}$. But, by Theorem 1 , $\Phi\left(\left(\bar{g}_{\mu, n} / \bar{f}_{\mu, n}\right)\right)=\Gamma\left(\Phi\left(x_{\mu}\right)\right)$ and $\Phi\left(\left(\bar{g}_{n} / \bar{f}_{n}\right)\right)=\Gamma(\Phi(x))$. Therefore,

$$
\Gamma\left(\Phi\left(x_{\mu}\right)\right) \longrightarrow \Gamma(\Phi(x))
$$

from which we may conclude that the function $\Gamma^{\circ} \Phi$ is continuous.

\section{REFERENCES}

1. J. Anthony, Topologies for quotient fields of commutative integral domains, Pacific J. Math., 36 (1971), 585-601.

2. L. Berg, Asymptotische Auffassung der Operatorenrechung, Studia Math., 21 (1962), 215-229.

3. T. K. Boehme, On Mikusinski operators, Studia Math., 33 (1969), 127-140.

4. W. A. Ditkin, On the theory of operational calculus, Dokl. Akad. Nauk SSSR, 123 (1958), 395-396.

5. J. Kelley, General Topology, Van Nostrand, Princeton, New Jersey, 1955.

6. G. Krabbe, Ratios of Laplace transforms, Mikusinski operational calculus, Math. Annalen, 162 (1966), 237-245.

7. — A very weak topology for the Mikusinski field, Notices Amer. Math. Soc., 19 (1972), 358.

8. J. Mikusinski, Operational Calculus, Pergamon Press, New York, 1959.

9. R. Struble, A genuine topology for the field of Mikusinski operators, Canad. Math. Bull., 11 (1968), 297-299.

Received April 26, 1972.

California State University, Fullerton 



\section{PACIFIC JOURNAL OF MATHEMATICS}

\section{EDITORS}

D. Gilbarg and J. Milgram

Stanford University

Stanford, California 94305

R. A. Beaumont

University of Washington

Seattle, Washington 98105
J. DUGUNDJI* Department of Mathematics

University of Southern California Los Angeles, California 90007

RICHARD ARENS

University of California

Los Angeles, California 90024

\section{ASSOCIATE EDITORS}

E. F. BeCKenbach

B. H. NeUMaNN

F. WOLF

K. Yoshida

\section{SUPPORTING INSTITUTIONS}

UNIVERSITY OF BRITISH COLUMBIA

UNIVERSITY OF SOUTHERN CALIFORNIA

CALIFORNIA INSTITUTE OF TECHNOLOGY

UNIVERSITY OF CALIFORNIA

MONTANA STATE UNIVERSITY

STANFORD UNIVERSITY

UNIVERSITY OF TOKYO

UNIVERSITY OF NEVADA

UNIVERSITY OF UTAH

NEW MEXICO STATE UNIVERSITY

WASHINGTON STATE UNIVERSITY

OREGON STATE UNIVERSITY

UNIVERSITY OF OREGON

OSAKA UNIVERSITY

UNIVERSITY OF WASHINGTON

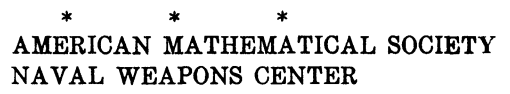

* C. DePrima will replace J. Dugundji until August 1974. 


\section{Pacific Journal of Mathematics}

\section{Vol. 47, No. $1 \quad$ January, 1973}

K. Adachi, Masuo Suzuki and M. Yoshida, Continuation of holomorphic

mappings, with values in a complex Lie group ....................

Michael Aschbacher, A characterization of the unitary and symplectic groups

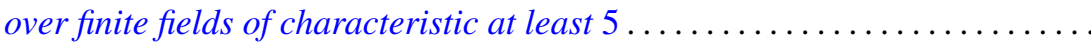

Larry Eugene Bobisud and James Calvert, Energy bounds and virial theorems for abstract wave equations....................................

Christer Borell, A note on an inequality for rearrangements ................

Peter Southcott Bullen and S. N. Mukhopadhyay, Peano derivatives and general

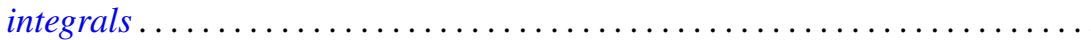

Wendell Dan Curtis, Yu-Lee Lee and Forrest Miller, A class of infinite dimensional subgroups of $\operatorname{Diff}^{r}(X)$ which are Banach Lie groups .........

Paul C. Eklof, The structure of ultraproducts of abelian groups ...............

William Alan Feldman, Axioms of countability and the algebra $C(X) \ldots \ldots \ldots$

Jack Tilden Goodykoontz, Jr., Aposyndetic properties of hyperspaces...........

George Grätzer and J. Płonka, On the number of polynomials of an idempotent algebra. II ...........................................

Alan Trinler Huckleberry, The weak envelope of holomorphy for algebras of

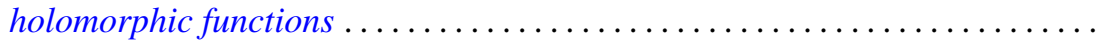

John Joseph Hutchinson and Julius Martin Zelmanowitz, Subdirect sum decompositions of endomorphism rings . . . . . . . . . . . . . . . .

Gary Douglas Jones, An asymptotic property of solutions of

$y^{\prime \prime \prime}+p y^{\prime}+q y=0$.

Howard E. Lacey, On the classification of Lindenstrauss spaces .

Charles Dwight Lahr, Approximate identities for convolution measure algebras.

George William Luna, Subdifferentials of convex functions on Banach

spaces.

Nelson Groh Markley, Locally circular minimal sets. .

Robert Wilmer Miller, Endomorphism rings of finitely generated projective modules

Donald Steven Passman, On the semisimplicity of group rings of linear

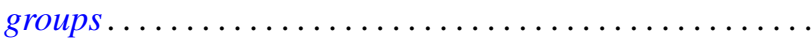

Bennie Jake Pearson, Dendritic compactifications of certain dendritic spaces.

Ryōtarō Satō, Abel-ergodic theorems for subsequences ...... .

Henry S. Sharp, Jr., Locally complete graphs. . .

Harris Samuel Shultz, A very weak topology for the Mikusinski field of

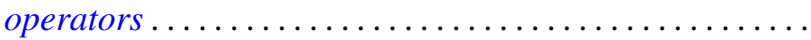

Elena Stroescu, Isometric dilations of contractions on Banach spaces ...

Charles W. Trigg, Versum sequences in the binary system ... . .

William L. Voxman, On the countable union of cellular decompositions of n-manifolds 